\title{
Functional aspects of small bowel transplantation: past, present, and future
}

Small bowel transplantation poses two major problems. Firstly, transplanting the small bowel between two unrelated individuals results in two different immunological reactions: host versus graft reaction (graft rejection) and graft versus host reaction. The large amount of transplanted lymphoid tissue is responsible for this highly immunogenic character of an intestinal allograft. Secondly, the surgical procedure of small bowel transplantation inevitably involves transection of the intestinal wall with intrinsic and extrinsic denervation, interruption of lymphatic drainage, and preservationinduced injury. Each component of this procedure may alter the intestinal physiology adversely. Immunological reactions and immunosuppressive agents may further compromise the normal intestinal functions. This review considers the functional aspects of experimental small bowel transplantation, with emphasis on enteric motility; hormonal, immunological, and nutritional aspects; and intestinal barrier function.

\section{Motor function}

In autotransplanted dogs, Ballinger showed altered small bowel motility by barium $x$ ray studied. ${ }^{1}$ In a syngeneic rat small bowel transplant model, Taguchi evaluated the effect of transplant on intestinal smooth muscle contractility and the associated neural control mechanisms, and found that neither the contractile properties of smooth muscle nor the responses to several neuropeptides, nor the excitatory response to electrical stimulation had changed. ${ }^{2}$ Inhibitory innervation did change, however, probably reflecting the degeneration of adrenergic nerve endings as a result of extrinsic denervation. He suggested that loss of one aspect of inhibition does not interfere with motility, because neural control of the small bowel seems to be predominantly intrinsic. ${ }^{2}$

In a dog model, Dennison reported normal intestinal myoelectrical activity by the second day after autografting and allografting, and recovery of intestinal transit by the 10th day after autografting. ${ }^{34}$ Others suggest that motor activity is absent for several weeks after autotransplantation in dogs. ${ }^{5-7}$ Subsequently, the autografted small bowel recovers the ability to generate normal migrating motor complexes, but the postprandial myoelectrical activity remains consistently and permanently absent. This suggests that the response to feeding is dependent on the integrity of the extrinsic nerves. ${ }^{5}$ However, infusion of the postprandial hormones, cholecystokinin (CCK) and pentagastrin, induced a normal pattern of contractions, suggestive of a modulating effect by hormones without imput from the extrinsic nerves. ${ }^{5}$

These changes in fasting or postprandial responses, or both, could result in luminal bacterial overgrowth, which might contribute to the failure of the small bowel graft and infectious complications. ${ }^{8}$

\section{Hormone function}

The gastrointestinal tract is innervated by a network of intrinsic and extrinsic neurons containing peptides. Changes in the content and amount of these neuropeptides in response to denervation after small bowel transplantation may have local and distant effects on small bowel functions, particularly since the gut is the largest endocrine organ of the body. ${ }^{9}$

Gebhardt examined the patterns of hormone distribution after heterotopic and orthotopic small bowel transplantation in rats. ${ }^{10}$ Heterotopic transplantation resulted in mucosal atrophy and a decrease in vasoactive intestinal peptide (VIP) and CCK concentrations. When the heterotopic graft was brought into the orthotopic position, however, these values returned to normal. LaRosa reported that small bowel transplantation, and thus extrinsic denervation, does not affect baseline intraluminal substance $\mathrm{P}$ and serotonin concentrations, or the physiological responses of these neuropeptides to intraluminal stimuli. ${ }^{11}$ Similar results were reported by Tietelbaum with somatostatin, VIP, and substance $P$ after syngeneic and allogeneic small bowel transplantation in rats. Progressive reduction in neuropeptides was seen only in cases of small bowel graft rejection. ${ }^{12}$ In contrast, Nelson showed that in vivo neural isolation of canine jejunoileum results in temporal adaptation of enteric neuropeptides. ${ }^{13}$ After extrinsic and intrinsic denervation, VIP and substance $\mathbf{P}$ concentrations were increased but neuropeptide $\mathrm{Y}$ values in both tissue and plasma were reduced. In addition, VIP and substance $\mathrm{P}$ concentrations increased progressively over time after surgery (198\% and $217 \%$ mean maximal increases, respectively). As VIP and substance $P$ induce a prosecretory effect, and neuropeptide $\mathrm{Y}$ a preabsorptive effect, this may have contributed to the profuse watery diarrhoea observed in this model. ${ }^{13}$ Nelson ascribed the discrepancy between his findings and other reports to the relatively short follow up in earlier studies. The altered neuropeptide concentrations after denervation may also modulate smooth muscle contractility and cause altered motility, as reported by Sarr. ${ }^{6}$

The exact role of denervation on gastrointestinal hormone concentrations has not yet been elucidated, but adaptive changes in the neuropeptides of the gut may alter the enteric physiology after transplantation. The influence of neuropeptides in modulating the gastrointestinal neuroimmune axis would be of interest since it has been shown that VIP exerts potent immunosuppressive actions via $T$ cell-specific mechanisms, which may play a role after transplantation. ${ }^{14}$

\section{Immune function}

The small bowel contains a large accumulation of lymphoid tissue in mesenteric lymph nodes, Peyer's patches, lamina propria, and epithelium. Little is known 
of the immune function of the transplanted small bowel, although it is obvious that long term survival with a graft necessitates a well functioning local immune system. ${ }^{15}$

In an effort to understand the immune function of transplanted small bowel, Xia and Kirkman reported a consecutive series of studies about specific secretory immunoglobulin A ( $\operatorname{IgA})$ production against cholera toxin in a rat small bowel transplantation model. ${ }^{16-20}$ They found no difference in total SIgA production after syngeneic or allogeneic small bowel transplantation, but noted that allografts are less effective in producing a primary $\operatorname{sIgA}$ response against cholera toxin than isografts. ${ }^{16}$ After priming the donor, however, small bowel allografts are capable of producing a secondary sIgA response to a booster of cholera toxin seven days after transplantation. ${ }^{17}$ Cyclosporin A treatment has no effect on total sIgA production, but it suppresses the sIgA response to cholera toxin in both allografts and isografts. ${ }^{18}$ This inhibitory effect of cyclosporin A lasts as long as the recipients are receiving it. In another experiment the authors showed that cyclosporin A only inhibits sIgA production against a $T$ cell dependent antigen such as cholera toxin, but not against a $T$ cell independent antigen (tinitrophenyl-lipopoly saccharide). ${ }^{19} \mathrm{Xia}$ suggested that this unresponsiveness against $\mathrm{T}$ cell dependent antigen cyclosporin $\mathrm{A}$ treated recipients explains the high incidence of septic complications after small bowel transplantation. Recently, he showed that priming of the recipient with cholera toxin before transplantation abrogates the inhibitory effect of cyclosporin A on specific sIgA production against cholera toxin. ${ }^{20}$ This finding may be relevant to clinical transplantation, since immunity against an infectious agent may occur after priming the transplantation candidate. This could mean that functional recipient lymphocytes repopulate the graft and produce the secondary immune response after boosting with cholera toxin.

\section{Nutritional function}

Small bowel transplantation is only worthwhile if the graft is capable of maintaining adequate nutrition in adult recipients, and normal growth and development in children without parenteral nutrition support. After an initial postoperative weight loss, rats regain normal weight after total isografting and allografting. ${ }^{21-23}$ Some investigators found normal weight gain even after a segmental small bowel graft consisting of either jejunum, ileum, or only part of the jejunum. ${ }^{212425}$ This suggests that transplanted small bowel has the ability to adapt, which had been confirmed by Kirsch, who found an increased diameter of the graft with hypertrophied villi. ${ }^{25}$ Kimura, De Bruin, and Oki designed fatal models of short bowel syndrome, in which transplantation of $40 \mathrm{~cm}$ of jejunum resulted in normal growth, whereas rats with a $20 \mathrm{~cm}$ jejunal graft showed suboptimal weight gain. ${ }^{22} 2627$

Small bowel transplantation in large animals has yielded more controversial data, probably because only occasional long term survivors have been reported. Dogs with a total autotransplant regained their pretransplant weight either soon or after a prolonged period. ${ }^{52829}$ However, several authors reported a 10 to $15 \%$ weight loss after total small bowel or $100 \mathrm{~cm}$ ileal autografting. ${ }^{40}$ Long term surviving dogs with a total small bowel allograft maintained their body weight, but after one year the weights of the two long term survivors reported by Diliz-Perez fell to a lower but eventually stable level. ${ }^{31} 32$ Transplantation of $100 \mathrm{~cm}$ ileal allografts in dogs by Collin resulted in $88 \%$ of pretransplant weights. $^{33}$ In contrast, pigs with a total small bowel allograft experienced a weight gain comparable with that of control pigs. ${ }^{34}{ }^{35}$ Kimura showed that pigs transplanted with a segmental jejunal allograft $(25 \%$ of total small bowel length) increased their body weight by almost $40 \%$ after six months, whereas all enterectomised control pigs suffered from malnutrition with progressive weight loss. ${ }^{36}$ Kimura concluded that porcine segmental small bowel allografts maintain their compensatory capacity and hypertrophy after massive small bowel reduction. Recently, we showed that dogs with a major histocompatibility complex (MHC) matched, orthotopic segmental graft, comprising 25 to $30 \%$ of total small bowel length, regained their preoperative body weight after 20 weeks. ${ }^{37}$ We are now performing orthotopic segmental small bowel transplants in immature dogs, which show a near normal weight gain (unpublished data).

\section{NUTRIENT ABSORPTION}

With regard to clinical small bowel transplantation, absorptive function of the transplanted bowel is the most important physiological determinant of graft function. It is likely that absorptive function after transplantation will be altered - at least temporarily - because of harvest injury, extrinsic denervation, transection of intrinsic neural continuity, and disruption of lymphatics. At present, however, intestinal absorptive function after transplantation is not fully understood and inconsistent studies have been reported. The different results may be explained by the varied experimental protocols. In addition, differences may be related to either the transplantation procedure itself or the immunological phenomena that follow.

Nutrient absorption studies after transplantation in rats showed prolonged malabsorption of fat and fat soluble vitamins ( $A$ and $E$ ), reduced uptake of glucose and glycine, and reduced glucose stimulated electrophysiological parameters. ${ }^{21} 2338$ Other rat studies showed normal faecal fat excretion, normal glucose and vitamin B-12 uptake, and relatively normal electrophysiological characteristics in non-rejecting small bowel grafts. ${ }^{21} 223940$

In dogs and pigs, absorptive functions of jejunum (D-xylose, folate), ileum (vitamin B-12), and jejunoileum (fat, fat soluble vitamins, cyclosporin A) have been studied in autotransplants and allotransplants. In a modified autotransplantation model without peritransplant ischaemia, Sarr showed normal D-xylose and folate absorption. ${ }^{30}$ Normal D-xylose absorption has also been reported in allotransplant experiments. ${ }^{41-43}$ This may suggest that absorption of D-xylose and folate does not require neural or lymphatic continuity. Several others reported reduced D-xylose absorption by small bowel allografts, but this could be related to rejection of the graft. ${ }^{31} 32$ The reduced D-xylose absorption found by Raju in autotransplants may be ascribed to bacterial overgrowth, because a similar phenomenon was found by other investigators in autotransplanted dogs that survived more than one year after transplant. 52829 This late malabsorption correlated with significant bacterial overgrowth, probably as a result of permanently impaired small bowel motility. ${ }^{29}$

Vitamin B-12 absorption and faecal fat excretion are normal in autografts and allografts in both dogs and pigs. 530343543 This suggests that vitamin B-12 absorption occurs without extrinsic and intrinsic neural and lymphatic continuity. Normal fat absorption in the presence of disrupted lymphatic drainage is of interest even in the early period after transplant. ${ }^{30} \mathrm{We}$ also found near normal faecal fat excretion in segmental orthotopic small bowel allografts in dogs. ${ }^{37} \mathrm{Re}$-establishment of lymphatic drainage occurs two weeks after small bowel transplantation, and is fully achieved by four to six weeks. ${ }^{44-47}$ An explanation for this 
early fat absorption may be the opening of lymphovenous communications in the mesentery if the lymphatic drainage is obstructed ${ }^{48}$ as a pathway for absorption of fat until the regenerated lymphatics take over. Impaired intestinal absorption of fat has been reported by Thompson in canine small bowel autotransplants more than 12 months after transplantation, probably because of bacterial overgrowth in the transplanted jejunum and ileum. ${ }^{29}$

Adequate cyclosporin $\mathrm{A}$ absorption in the small bowel is vital for a recipient with an allograft. ${ }^{22} 4449$ Cyclosporin A is a lipophilic agent and is absorbed through the lymphatic drainage. Schraut suggested that cyclosporin A absorption in the early period after transplant may be compromised because of disrupted lymphatics. ${ }^{50}$ This has been underlined by investigators who found a low incidence of small bowel graft rejection if cyclosporin $\mathrm{A}$ was administered parenterally in the peritransplant period. ${ }^{34} 35$ Other investigators found normal cyclosporin $\mathrm{A}$ absorption after oral or intraluminal treatment, even in the first week after transplant. 225152 Cohen explained this by cyclosporin A absorption via the peritoneal membrane. ${ }^{53}$ According to Cohen, cyclosporin A leaks into the peritoneal cavity through the disrupted lymphatics, after which it is absorbed. It may be that cyclosporin $A$ is absorbed via lymphovenous anastomoses in the mesentery. However, during the early period after transplant it seems justified to treat the recipient with parenteral cyclosporin $\mathrm{A}$, because plasma concentrations may be unpredictable during this time and rejection episodes will impair the absorptive capacity for cyclosporin A. ${ }^{49} 54$ Complicating factors may be that cyclosporin $\mathrm{A}$ itself reduces nutrient absorption and adversely affects the microvasculature of the small bowel. 5556

\section{WATER AND ELECTROLYTE ABSORPTION}

Several studies in rats have shown that net absorption of electrolyte solutions is decreased early after small bowel transplantation. ${ }^{37} 57$ Extrinsic denervation may be the underlying cause, since denervated small bowel secretes water and chloride from the crypts as a consequence of loss of sympathetic input. ${ }^{58} 59$ Using electrophysiological measurements we found indirect evidence that extrinsic denervation leads to increased secretory activity of the crypts in a heterotopic autotransplant model in dogs. ${ }^{60} \mathrm{It}$ has been suggested that extrinsic denervation after small bowel transplantation plays a much more important part in the fluid and electrolyte balance than in the absorption of nutrients. Watson found that glucose can reverse the secretory state found with isotonic saline, which implies that glucose electrolyte solutions may be clinically useful in promoting electrolyte absorption after transplantation. ${ }^{37}$ Sigalet observed an increase in sodium/glucose cotransporter activity after small bowel transplantation, which may be compensatory and restore the electrolyte balance. ${ }^{23}$ However, a recent canine study found no significant effect on jejunal absorption using a balanced physiological saline solution before or after transplant. ${ }^{61}$ At present, it is uncertain whether regeneration of extrinsic neural continuity or adaptation to chronic denervation takes place.

\section{Barrier function}

Impaired gut barrier function is a possible aetiological factor in the development of multiorgan failure. ${ }^{62}$ The high incidence of infectious complications and sepsis after small bowel transplantation may be a result of excessive immunosuppression, but a compromised barrier function of native or grafted small bowel may also be important. We evaluated the mucosal integrity of acute rejecting intestinal grafts by analysing albumin contents in the graft effluent and found a protein losing enteropathy corresponding with rejection, which suggests that the mucosa barrier is highly permeable during a rejection episode. ${ }^{63}$

In a study in rats Grant showed that rejection of orthotopic small bowel grafts leads to increased intestinal permeability to ${ }^{51} \mathrm{Cr}$-EDTA and increased bacterial translocation from the lumen of the graft to the host's mesenteric lymph nodes, liver, and spleen ${ }^{64} \mathrm{He}$ proposed that bacterial translocation may stimulate immune responses, which contributes to the intensity and rapidity of small bowel graft rejection. In a heterotopic rat model, Fabian reported increased bacterial translocation not only in small bowel allografts, but also in isografts, suggesting that the transplantation process itself affects the intestinal permeability independently of rejection. ${ }^{65}$ Browne showed that the transplantation procedure itself leads to Gram negative aerobic overgrowth within the transplanted small bowel segment and ascending colon. ${ }^{66}$ Significant translocation of bacteria to the mesenteric lymph nodes occurred only when cyclosporin A was added. Remarkably, Gram negative organisms were more commonly isolated from the native mesenteric lymph nodes that from the graft, which suggests translocation through both native and transplanted small bowel. ${ }^{66}$ Cyclosporin A facilitates distant dissemination to liver, spleen, and lung once translocation has occurred. Therefore, both bacterial overgrowth and immunosuppression are associated with translocation and sepsis after small bowel transplantation.

\section{Future directions}

Future research should be directed to a better understanding and prevention of acute and chronic rejection. The induction of specific tolerance or improved immunosuppressive agents may be a prerequisite for the success of clinical transplantation. MHC matching may be valuable in reducing the vigorous immunosuppressive regimen. ${ }^{37}$ In addition, MHC matching may pave the way for livingrelated intestinal transplantation.

New approaches to prevent infectious complications and to enhance the mucosal barrier should be considered. In this context selective gut decontamination, early enteral feeding, and modified total parenteral nutrition may be important tools. Potential beneficial effects of glutamine, short chain fatty acids, and polyamines added to enteral or parenteral nutrition should be investigated. ${ }^{67-70}$

The possible protecting effect of a liver graft in conjunction with a small bowel graft is an important issue..$^{71-73}$ Although experimental studies and one clinical case showed the superiority of combined small bowel liver transplantation, this benefit could not be confirmed in the first reported series of intestinal transplantation either in composite visceral grafts or alone. ${ }^{71-74}$ The convalescence of the eight patients who received an intestinal graft alone was more trouble free than after small bowel liver or multivisceral transplantation, with no greater difficulty in control of rejection. ${ }^{74}$ This suggests that small bowel liver transplantation should be reserved for specific indications, such as coexisting liver failure from total parenteral nutrition or a hepatic inborn error of metabolism. It is too early, however, to predict the function of the chronically tolerated intestinal graft, whether transplanted alone or as part of an organ complex.

Recent clinical small bowel transplantations should be critically evaluated. ${ }^{71} 74$ The combination of extending our experimental knowledge and clinical experience should 
eventually result in safe clinically effective transplantation from both immunological and functional points of view.

M A C MEIJSSEN

University Hospital Dijkzigt,

Department of Internal Medicine II,

Dr Molewaterplein 40,

NL-3015 GD Rotterdam,

The Netherlands

University Hospital Maastricht,

E HEINEMAN

Department of Surgery,

Maastricht,

The Netherlands

Correspondence to: Dr M A C Meijssen.

1 Ballinger WF, Christy MG, Ashby W. Autotransplantation of the small intestine. Surgery 1962; 52: 151-64.

2 Taguchi T, Zorychta E, Sonnino RE, Guttman FM. Small intestinal transplantation in the rat: Effect on physiological properties of smooth muscle plantation in the rat: Effect on physiological p

3 Dennison AR, Collin J, Watkins RM, Millard PR, Morris PJ. Segmental small intestinal allografts in the dog. I. Morphological and functional small intestinal allografts in the dog. I. Morphologica
indices of rejection. Transplantation 1987; 44: 474-8.

4 Dennison AR, Collin J, Watkins RM, Millard PR, Morris PJ. Absorptive and motor function of orthotopically vascularized segmental ileal autografts. Br F Surg 1987; 74: 187-91.

5 Quigley EMM, Thompson JS, Rose SG. The long-term function of canine jejunoileal autotransplants - Insights into allograft physiology. Transplant Proc 1992; 24: 1105-6.

6 Sarr MG, Kelly KA. Myoelectric activity of the autotransplanted canine jejunoileum. Gastroenterology 1981; 81: 303-10.

7 Sarr MG, Duenes JA, Tanaka M. A model of jejunoileal in vivo neural isolation of the entire jejunoileum: Transplantation and the effects on isolation of the entire jejunoileum: Transplant
intestinal motility. $\mathcal{F}$ Surg Res $1989 ; 47: 266-72$.

8 Vantrappen G, Janssens J, Hellemans J, Ghoos Y. The interdigestive motor complex of normal subjects and patients with bacterial overgrowth of the small intestine. $\mathcal{F}$ Clin Invest 1977; 59: 1158-66.

9 Thompson JC, Marx M. Gastrointestinal hormones. Curr Probl Surg 1984; 21: 1

10 Gebhardt JH, Preissner WC, Deltz E, Kaiserling E, Müller-Hermelink HK. Patterns of gastrointestinal hormone distribution after small-bowel transplantation. In: Deltz E, Thiede A, Hamelmann H, eds. Small-bowel transplantation. Experimental and clinical fundamentals. Berlin: SpringerVerlag, 1986: 84-6.

11 LaRosa CA, Kimura K, Dresner LS, Birnbaum E, Jaffe BM. The effect of small intestinal transplantation on intraluminal levels of serotonin and substance P. I Surg Res 1989; 46: 600-4.

12 Teitelbaum DH, O'Dorisio TM, Qualman SJ, Sonnino RE, Dunaway DJ, Harmel RP. Alteration in gastrointestinal peptide tissue levels in rejecting small bowel transplants. Ұ Pediatr Surg 1989; 24: 629-33.

13 Nelson DK, Sarr MG, Go VLW. In vivo neural isolation of canine jejunoileum: Temporal adaptation of enteric neuropeptides. Gut 1991; 32: $1336-41$.

14 Ottaway CA. Selective effects of vasoactive intestinal peptide on the mitogenic response of murine T cells. Immunology 1987; 62: 291-7.

15 Arnaud-Battandier F, Salmon H, Aynaud JM, Bernard S, Revillon Y, Ricour C. In vitro and in vivo studies of the mucosal immune barrier after long-term small-bowel allotransplantation in pigs using cyclosporine. In: Deltz E, Thiede A, Hamelmann H, eds. Small-bowel transplantation. Experim

$16 \mathrm{Xia}$ W, Kirkman RL. Immune function in transplanted small intestine. Total secretory IgA production and response against cholera toxin. secretory IgA production and
Transplantation 1990; 49: 277-80.

$17 \mathrm{Xia} \mathrm{W}$, Kirkman RL. Immune function in transplanted small intestine. II. sIgA production in cholera toxin-primed rats. Transplant Proc 1990; 22: 2481-2.

$18 \mathrm{Xia}$ W, Kirkman RL. Inhibitory effect of cyclosporine on specific secretory IgA production against cholera toxin in small bowel transplantation. Transplant Proc 1991; 23: 682-3.

19 Xia W, Kirkman RL. Cycloporine inhibits specific sIgA production against cholera toxin but not trinitrophenyl-lipopolysaccharide in small bowel transplantation. Transplant Proc 1992; 24: 1155-6.

$20 \mathrm{Xia}$ W, Kirkman RL. Priming the recipient abrogates the inhibitory effect of cyclosporine on specific sIgA production against cholera toxin in small bowel transplantation. Transplant Proc 1992; 24: 1139-40.

21 Schraut WH, Lee KKW, Sitrin M. Recipient growth and nutritional status following transplantation of segmental small-bowel allografts. $\mathcal{f}$ Surg Res 1987; 43: 1-9.

22 De Bruin RWF, Heineman E, Jeekel J, Meijssen MAC, Lindemans J, Bonthuis F, Marquet RL. Functional aspects of small-bowel transplantation in rats. Scant $\mathcal{f}$ Gastroenterol 1992; 27: 483-8.

23 Sigalet DL, Kneteman NM, Fedorak RN, Kizilisik AT, Thomson ABR. Intestinal function following allogeneic small intestinal transplantation in the rat. Transplantation 1992; 53: 264-71.

24 Kimura K, Money SR, Jaffe BM. Short-segment orthotopic intestinal isografts and allografts in enterectomized rats. Transplantation 1987; 44: 579-82.

25 Kirsch AJ, Kirsch SS, Kimura K, LaRosa CA, Jaffe BM. The adaptive ability of the transplanted rat small bowel. Surgery 1991; 109: 779-87.

26 Kimura K, LaRosa CA, Money SR, Jaffe BM. Segmental intestinal transplantation in rats with resected entire small bowel, ileocecal valve and cecum. F Surg Res 1988; 45: 349-56.

27 Oki K, Maeda K, Nakamura K. Orthotopic small intestine transplantation in the rat: How long a small intestinal graft is necessary? Transplant Proc 1989; $21: 2909-12$.

28 Raju S, Fujiwara H, Grogan JB, Achord JL. Long-term nutritional function of orthotopic small bowel autotransplants. $\mathcal{f}$ Surg Res 1989; 46: 142-6.
29 Thompson JS, Rose SG, Spanta AD, Quigley EMM. The long-term effect of jejunoileal autotransplantation on intestinal function. Surgery 1992; 111: $62-8$.

30 Sarr MG, Duenes JA, Walters AM. Jejunal and ileal absorptive function after a model of canine jejunoileal autotransplantation. $\mathcal{f}$ Surg Res 1991; 51: 233-9.

31 Reznick RK, Craddock GN, Langer B, Gilas T, Cullen JB. Structure and function of small bowel allografts in the dog: Immunosuppression with cyclosporin A. Can f Surg 1982; 25: 51-5.

32 Diliz-Perez HS, McClure J, Bedetti C, Hong H, de Santibanes E, Shaw BW, et al. Successful small bowel allotransplantation in dogs with cyclosporine and prednisone. Transplantation 1984; 37: 126-9.

33 Collin J, Dennison AR, Watkins RM, Millard PR, Morris PJ. Segmental small intestinal allografts. II. Inadequate function with cyclosporine
immunosuppression: Evidence of a protein losing enteropathy. immunosuppression: Evidence

34 Grant D, Duff J, Zhong R, Garcia B, Lipohar C, Keown P, Stiller C. Successful intestinal transplantation in pigs treated with cyclosporine. Transplantation 1988; 45: 279-84

35 Kaneko H, Hancock W, Schweizer RT. Progress in experimental porcine small- bowel transplantation. Arch Surg 1989; 124: 587-92.

36 Kimura K, LaRosa CA, Blank MA, Jaffe BM. Successful segmental intestinal transplantation in enterectomized pigs. Ann Surg 1990; 211: 158-64.

37 Meijssen MAC, Heineman E, De Bruin RWF, Wolvekamp MCJ, Marquet RL, Molenaar JC. Long-term survival of DLA-matched segmental small bowel allografts in dogs. Transplantation 1993; 56: 1062-6.

38 Watson AJM, Lear PA, Montgomery A, Elliot E, Dacre J, Farthing MJG, Wood RFM. Water, electrolyte, glucose, and glycine absorption in rat small intestinal transplants. Gastroenterology 1988; 94: 863-9.

39 Madara JL, Kirkman RL. Structural and functional evolution of jejunal allograft rejection in rats and the ameliorating effects of cyclosporin therapy. $\mathcal{f}$ Clin Invest 1985; 75: 502-12.

40 Schroeder P, Sandforth F, Deltz E. Glucose absorption after heterotopic small-bowel transplantation. In: Deltz E, Thiede A, Hamelmann H, eds. Small-bowel transplantation. Experimental and clinical fundamentals. Berlin: Springer-Verlag, 1986: 74-8.

41 Ricour C, Revillon Y, Arnaud-Battandier F, Ghnassia D, Weyne P, Lauffenburger A, et al. Successful small bowel allografts in piglets using cyclosporine. Transplant Proc 1983; 15: 3019-26.

42 Toledo Pereyra LH, Simmons RL, Najarian JS. Absorption of carbohydrates and vitamins in the preserved and transplanted small intestine. Am $\mathcal{F}$ Surg 1975; 129: 192-7.

43 Benchimol D, Pesce A, Delque-Bayer P, Saint-Paul MC, Giudicelli J, Mouroux J, et al. Jejunal versus ileal segmental allografts in the dog: Comparison of immunologic and functional results. Surgery 1992; 112: 918-27.

44 Mackenzie R, Nordgren S, Lossing A, Craddock G, Cohen Z, Stiller C, Langer B. Cyclosporin A absorption in canine small intestinal transplantation. Transplant Proc 1982; 14: 646-8.

45 Kocandrle V, Houttuin E, Prohaska JV. Regeneration of the lymphatics after autotransplantation and homotransplantation of the entire small intestine. Surg Gynecol Obstet 1966; 122: 587-92.

46 Schmid T, Korozsi G, Oberhuber G, Klima G, Margreiter R. Lymphatic regeneration after small-bowel transplantation. Transplant Proc 1990; 22: 2446

47 Goott B, Lillehei RC, Miller FA. Mesenteric lymphatic regeneration after autografts of small bowel in dogs. Surgery 1960; 48: 571-5.

48 Rotman N, Michot F, Hay JM, Fagniez PL. Lymphatic regeneration following intestinal transplantation in the pig. In: Deltz E, Thiede A, Hamelmann H, eds. Small-bowel transplantation. Experimental and clinical fundamentals. Berlin: Springer-Verlag, 1986: 34-6.

49 Wassef R, Cohen Z, Nordgren S, Langer B. Cyclosporine absorption in intestinal transplantation. Transplantation 1985; 39: 496-9.

50 Schraut WH. Current status of small-bowel transplantation. Gastroenterology 1988; 94: 525-38.

51 Aeder MI, Payne WD, Jeng LB, Sutherland DER, Najarian JS. Use of cyclosporine for small in

52 LaRosa CA, Kimura K, Dresner LS, Birnbaum E, Jaffe BM. Cyclosporine absorption by transplanted rat small intestine. Transplantation 1989; 47: 736-8.

53 Cohen Z, Nordgren SR, Mackenzie RD, Lossing AG, Stiller CR, Langer B. Pharmacokinetics of cyclosporine in a canine intestinal transplantation model. Transplant Proc 1983; 15: 3013-8.

54 Atkinson K, Boland J, Britton J, Biggs J. Blood and tissue distribution of cyclosporine in humans and mice. Transplant Proc 1983; 15: 2430-3.

55 Sigalet DL, Kneteman NM, Thomson ABR. Reduction of nutrien absorption in normal rats by cyclosporine. Transplantation 1992; 53: 1103-7.

56 Crane PW, Ingham-Clark CL, Davies RL, Slavin G, Wood RFM, Lear PA. Cyclosporine toxicity in the small intestine. Transplant Proc 1990; 22: 2432.

57 Nemeth MA, Harris MS, Ramaswamy K, Schraut WH, Sarna SK, Cordon RE, Telford GL. Rat small intestinal isografts have normal fasted and fed myoelectric activity and decreased absorptive capacity. Dig Dis Sci 1987; 32: 923 .

58 Donowitz M, Welsh MJ. Regulation of mammalian small intestinal electrolyte secretion. In: Johnson LR, ed Physiology of the gastrointestinal electrolyte secretion. In: Johnson LR, ed. Physiology of the gastr
tract. 2nd ed. Vol 2. New York: Raven Press, 1987: 1351-88.

59 Jodal M. Neuronal influence on intestinal transport. $\mathcal{F}$ Intern Med 1991; 228: 125

60 Meijssen MAC, Heineman E, De Bruin RWF, Veeze HJ, Bijman J, De Jonge $H R$, et al. Value of in vivo electrophysiological measurements to evaluate canine small bowel autotransplants. Gut 1991; 32: 1329-35.

61 Hakim NS, Walters AM, Dalton RR, Twomey CK, Sarr MG. Canine jejunoileal (auto)transplantation: Effect on jejunal absorption of water, electrolytes, and glucose. Gastroenterology 1990; 98: A173.

62 Wilmore DW, Smith RJ, O'Dwyer ST, Jacobs DO, Ziegler TR, Wang X. The gut: A central organ after surgical stress. Surgery 1988; 104: 917-23.

63 Meijssen MAC, Heineman E, De Bruin RWF, Marquet RL, Molenaar JC. Diminished functional capacity and compromised mucosal integrity in acute rejecting DLA-matched and mismatched canine small-bowel allografts. Transplant Proc 1992; 24: 11 16-7. 
64 Grant D, Hurlbut D, Zhong R, Wang P, Chen H, Garcia B, et al. Intestinal permeability and bacterial translocation following small bowel transplantation in the rat. Transplantation 1991; 52: 221-4.

65 Fabian MA, Bollinger RR. Rapid translocation of bacteria in small bowel transplantation. Transplant Proc 1992; 24: 1103

66 Browne BJ, Johnson CP, Edmiston CE, Hlava MA, Moore GH, Roza AM, et al. Small bowel transplantation promotes bacterial overgrowth and translocation. F Surg Res 1991; 51: 512-7.

67 Souba WW, Herskowitz K, Augsten TR, Chen MK, Salloum RM. Glutamine nutrition: theoretical considerations and theoretic impact. fournal of Parenteral and Enteral Nutrition 1990; 14: S237-43.

68 Kripke SA, De Paula JA, Berman JM, Fox AD, Rombeau JL, Settle RG. Experimental short-bowel syndrome: Effect of an elemental diet suppleExperimental short-bowel syndrome: Effect of an elemental diet supple69 Koruda MJ, Rolandelli RH, Settle RG, Zimmaro DM, Rombeau JL. Effect of parenteral nutrition supplemented with short-chain fatty acids on adaptation to massive bowel resection. Gastroenterology 1988; 95: $715-20$

70 Luk GD, Yang P. Distribution of polyamines and their biosynthetic enzymes in intestinal adaptation. Am $\mathcal{F}$ Physiol 1988; 254: G194-200.

71 Grant D, Wall W, Mimeault R, Zhong R, Ghent C, Garcia B, Stiller C Duff J. Successful small bowel/liver transplantation. Lancet 1990; 335: $181-4$.

72 Li X, Zhong R, He G, Sakai Y, Quan D, Garcia B, Duff J, Grant D. Host immunosuppression after combined liver/intestine transplantation in the rat. Transplant Proc 1992; 24: 1206-7.

73 Sarnacki S, Cerf-Bensussan N, Revillon Y, Calise D, Goulet O, Ricour C, Brousse N. Long-term small bowel graft survival induced by sponBrousse N. Long-term small bowel graft survival induced by

74 Todo S, Tzakis AG, Abu-Elmagd K, Reyes J, Nakamura K, Casavilla A et al. Intestinal transplantation in composite visceral grafts or alone. Ann Surg 1992; 216: 223-34.

\section{Gastrointestinal endoscopy in general practice}

The summary of the report of a working party of the endoscopy section of the British Society of Gastroenterology is printed here.

Increasing emphasis on primary care in the NHS has prompted suggestions that a number of services should be provided in general practice. The report considers the possibility of providing gastrointestinal endoscopy in general practice.

Commissioners of health care are responsible for ensuring access to high quality, safe, endoscopic services. Careful consideration of the safety of potential providers, as well as the capital and revenue costs is essential: duplication of services must be avoided.

For the safety of both patients and staff, the following standards must be met wherever endoscopy is performed:

1 Endoscopists must be adequately trained. Endoscopic and interpretive skills must be maintained by a sufficient workload and continuing interaction with other endoscopists and specialists.

2 Adequate equipment must be available, together with safe facilities for its cleaning and maintenance.

3 Providers must adhere to professional guidelines for sedation, monitoring, and recovery.

4 There must be sufficient numbers of trained and experienced support staff.

5 A safe environment must be provided, to comply with
Health and Safety Executive and Control of Substances Hazardous to Health regulations.

6 Anaesthetic and resuscitation facilities must be provided on site for the management of complications of sedation and procedures, particularly for patients at risk because of age or medical condition.

Because of the risks, therapeutic gastroscopy, colonoscopy, endoscopic retrograde cholangiopancreatography, and endoscopy in children should be confined to hospitals, where support for the management of complications is present.

The working group concluded that providers of endoscopy must conform to standards both of safety for staff and patients and of the quality of the services. Some endoscopic procedures could be provided in general practice if these standards are met. It seems likely, however, that it would not be possible or cost effective to provide the level of support required for anything other than routine diagnostic gastroscopy and flexible sigmoidoscopy in fit adults and even there, the case is in doubt.

Copies of the full report may be obtained from the Secretary, British Society of Gastroenterology, 3 St Andrews Place, London NW1 4LB.

Members of the endoscopy section working party

E T Swarbrick (chairman), Wolverhampton; R F McCloy, Manchester; A T R Axon, Leeds; A I Morris, Liverpool; M D Hellier, Swindon; R J Barnes, Gloucester; M L W Gear, Gloucester. 